\title{
Reference Virtual Design Team (VDT) probabilities to Design Construction Project Organizations
}

\author{
Parámetros de referencia de Virtual Design Team (VDT) para el diseño de organizaciones de proyectos \\ de construcción.
}

Marcelo Concha (Main Author)

Pontificia Universidad Católica de Chile/Facultad de Ingeniería/ Departamento de Ingeniería y Gestión de la Construcción, Chile miconch1@uc.cl

\section{Luis Fernando Alarcón (Contact Autor)}

Pontificia Universidad Católica de Chile/Facultad de Ingeniería/ Departamento de Ingeniería y Gestión de la Construcción, Chile Vicuña Mackenna 4860, Santiago, Chile

(+56) 223547165

lalarcon@ing.puc.cl

\begin{abstract}
This paper reports the results obtained from five virtual models of construction project organizations developed using the Virtual Design Team (VDT) method. The results were compared with the real project organization performance in each case and their probabilities inputs were calibrated to obtain benchmark reference inputs for future projects. The models were validated comparing their predictions with real results obtained in the projects and the predicted behavior of the organizations was subjected to the assessment and approval of technical experts of the companies in the study. The calibrated models obtained represent reality within appropriate margins given the variable nature of the problem, being able to predict the performance of projects with results generally less than $5 \%$ difference between the real performance and modeling results, achieving probabilities close to those from literature and well received by companies in the structured interview, with over $70 \%$ approval in the predicted factors covered. These results contribute to expand the uses of VDT methodology and to adapt this methodology to local companies, which enables to model organizations at the planning and design phase, achieving improvements in terms of cost, schedule and quality risks.
\end{abstract}

Keywords: Organizational Design, Virtual Design Team, Virtual Modeling.

\section{Introduction}

The organizational design has shown significant progress in recent decades thanks in part to the efforts of a group of researchers from the Stanford Center for Integrated Facility Engineering (CIFE), which has developed a methodology and computational tools to help companies to design project organizations. This methodology is based on taking into account the work and coordination efforts as information and communication processing activities (Galbraith, 1974). These efforts resulted in a framework and modeling system called Virtual Design Team (VDT), in which rational agents process information associated with direct labor, redone work, coordination and waiting times for decisions (Levitt \& Kunz, 2002). In parallel, a theory of production determined by a set of processing activities and processes that add value flow (Koskela, 2000) emerged. So far there is no field developed with concrete examples and applications that serve to link the Koskela's theory with VDT. For this reason, the objectives of this study are: 1 Predicting the performance of construction projects through the design of organizations with virtual modeling projects using the concepts of VDT; 2 . Calibrate the input parameters to represent the organizations studied as a basis for future projects; and 3.- Validate the results obtained. The modeling software used is SimVision, an environment that enable to simulate project organizations.

\section{Claudio Mourgues}

Pontificia Universidad Católica de Chile/Facultad de Ingeniería/ Departamento de Ingeniería y Gestión de la Construcción, Chile cmourgue@ing.puc.cl

\author{
Manuscript Code: 361 \\ Date of Reception/Acceptance: 30.04.2014/01.06.2015
}

\section{Resumen}

Este paper muestra los resultados obtenidos en cinco modelos virtuales de organizaciones de proyectos de construcción utilizando la metodología Virtual Design Team (VDT). Los resultados fueron comparados con los resultados reales de cada proyecto en cada caso y sus probabilidades de entrada fueron calibradas para obtener datos de entrada de referencia para proyectos futuros. Los modelos fueron validados a través de la comparación de las predicciones con los resultados reales de los proyectos y los ajustes respectivos para disminuir las brechas, y a través de la aprobación de los expertos técnicos de las empresas del estudio. Los modelos obtenidos representan la realidad dentro de márgenes razonables, dada la naturaleza variable del problema, siendo capaces de predecir los resultados con un rango menor a un $5 \%$ de diferencia entre lo real y lo simulado, logrando probabilidades cercanas a las encontradas en literatura y obteniendo más del $70 \%$ de aprobación en el total de factores analizados. Estos resultados contribuyen a expandir los usos de la metodología VDT y a adaptarla a las empresas locales, lo que les permitirá modelar sus organizaciones en la fase de planificación y diseño, logrando mejoras en términos de costo, programa y riesgos de calidad.

Palabras Claves: Diseño Organizacional, Equipo de Diseño Virtual, Modelación Virtual.

Problem Description

Competitiveness relates to having better abilities and capabilities than competitors, and it involves both results achieved in the past and the perception of future potential of a Company (Orozco et. al., 2011). The current conditions in the construction industry, are characterized by a decline in project tenders, has prompted the search for new ways to increase their competitiveness. However, in this area in particular, there are some issues that need to be addressed, such as insufficient growth in productivity, low adoption of new technologies and inadequate planning control.

\section{Low or insufficient productivity}

The industry has a low productivity growth if compared with other sectors, such as mining, agriculture and manufacturing (Magendzo \& Villena, 2012). This situation motivates companies to seek new ways to manage their projects in order to obtain better productivity and enhance their competitiveness.

\section{Low adoption of new technologies}

In general, the construction industry is backward in relation to the technological development achieved in other industries in Chile and also compared to the level of construction technology developed in other countries. This slow adoption is attributed to: i) risk aversion of the construction companies, ii) its competitors are also conservative, iii) till now they had not 
found the need to improve their processes and profitability, and this has changed in recent times (Ghio \& Bascuñan, 2012). Complementing this, the industry has a lack of procedures and conditions to promote the adoption of new technologies. This ranges from the culture of the people in organizations till the use of new technological tools and new processes manuals.

\section{Inadequate or poorly controlled planning}

Both in the design phase and in the monitoring of projects. Usually items are neglected during the implementation and monitoring of activities is lost, generating instances that must be resolved at the time, urgently, increasing costs (Serpell et al., 2007). Similarly, there is a lack tools or mechanisms to anticipate problems, taking preventive decisions or knowing which path to follow to lessen the impacts of undesirable situations.

\section{Background}

Usually in planning studies, activities are only planned by a mere assignment of responsibility based on performance, without considering its impact in terms of skills, experience, communication with coworkers, direct control, among others. This perspective has its parallel in the traditional production theory, because it is simply based on analyzing each activity as a process of transformation, splitting it into sub-processes, which must be performed in a ratio of performance. Furthermore, projects are affected by variability, directly affecting its performance. One of the previous studies related to variability in construction, was related to programming buffers (Gonzalez \& Alarcon, 2003). The buffers try to cover spaces that usually occupy different nature eventualities that may occur in the course of a project. It was shown that Buffers help to reduce the impact of variability in projects and a programming methodology based in buffers in repetitive projects to reduce variability was proposed. In the extent that variability could be reduced, possibly smaller buffers would be required.

Planners try to protect themselves from variability incorporating slacks that allow adapt the project to unforeseen conditions. However, this variability, which is generally unknown, can be quantified in part by incorporating productive theory proposed by Koskela, as it consider other activities as flow processes, which can be measured and reduced to the extent some associated variables could be controlled (as communication, coordination, centralization, among others).

There is a methodology, called Virtual Design Team (VDT), which allows modeling direct work, rework, coordination and waiting times for decisions. Virtual models of VDT have been used in studies of interventions with SimVision, from the perspective of the analysis of different organizational configurations to run projects under a look of iterations to achieve the desired cost, time and quality targets. For example, in predicting project efficiency and quality of work processes (Kunz, Levitt \& Thomsen, 1997), computational experiments (Nissen \& Buettner, 2004) and also in other overseas projects, for example, in NASA projects (Carroll et.al., 2006) and in Redevelopment and Construction projects of the European Bank (Levitt et al., 2002). They also are being used for educational purposes, teaching students to use the program by modeling problem cases (ePM LLC, 2002). However, till date there are no initiatives using the program in Chile and adapting the methodology to local conditions.
In addition, you can find other programs that have similar features to SimVision, such as ORGAHEAD (Louie, 2002), which was used in a study to verify the output data that Simvision threw in a given project. Despite using the same input data, interface and operation are different: it is a model of organizational learning, that tests the ability of an organization to perform certain activities from different ways, and to adapt to their environment, heuristically. There are also other approaches using VDT that allow successive iterations to try to optimize organizational configurations, through obtaining lower output variables values in each iteration. This is called genetic programming (Khosraviani \& Levitt, 2005).

As the lector could see here, there are other programs with alternative features and there are also different approaches to using the tool. For example, a study abroad with SimVision investigated a construction process from the design stage to the operation, obtaining input VDT probabilities that represents characteristics of the organization studied (Ibrahim \& Nissen, 2004). This approximation of the tool is to be used locally to obtain input parameters that can be characteristic of Chilean organizations.

\section{Virtual Design Team (VDT)}

The Virtual Design Team methodology (VDT) was created to allow project managers to design project organizations (Levitt et al., 2002), i.e., to model and simulate multiple alternative configurations to predict and assess their performance prior to implementation (Levitt, 2009). VDT was based on the notion that the prime determinant of the success of an organization is its ability to process information associated with Direct Labor, Work Coordination and Institutional Work. The Direct Labor is the amount of work that a worker has to do in their assigned activity. Work Coordination, in the case of VDT, involves work that is generated by Rework caused by a task, coordination between agents performing related tasks, and decision wait times from supervisors. And finally, the Institutional Work, corresponding to values and goals of individuals, their confrontation with the organization ones, external policies and laws, among others.

\section{VDT and organizational design}

VDT established four fundamental probabilities that determine the different levels of information processing within the organization, in terms of direct labor, exceptions and decision-making, participation in meetings and external noise affecting daily work. These probabilities are (EPM 2005): Information Exchange Probability, Noise Probability, Functional Error Probability and Error Project Probability. VDT intended to model organizations so that it is possible to include changes in them to analyze the impacts on project performance. Here comes again Galbraith with Contingency Theory (Galbraith, 1974), which is precisely about that project organizations must adapt to the conditions of the project and the environment. Taking the above into consideration and based on the extensive literature on organizational design, VDT take into account four main aspects: Team Experience, Centralization, Formalization and Matrix Strength. The program has a number of features that allow to refine details of modeling. For example, modeling the experience of workers or the uncertainty of the information necessary to perform an activity, that way before starting an activity, information is available for workers.In general, these aspects involve input parameters and elements that allow to characterize the organization, on a macro and micro level, so as to establish conditions of the scenarios studied. 
A production theory for transformation, flow and value processes

The coordination work mentioned above is related to the production theory about transformation processes mixed with flow processes (Koskela, 2000). There are three views on production, on the one hand is the view of production as a transformation; the second sight has main focus on what happens between threads (what happens between changes, i.e. flow processes), where inspections or material transfers occurs and that are not processing activities; and there is a third aspect that looks the production process as a process of value creation. The Koskela's production theory integrates these three views, creating what is called the concept of production as transformation, flow and value generation.

\begin{tabular}{|c|c|c|c|}
\hline \multirow{2}{*}{$\begin{array}{c}\text { VDT } \\
\text { elements }\end{array}$} & \multicolumn{3}{|c|}{ Lean Construcion elements } \\
\hline & Transformation & Flow & $\begin{array}{c}\text { Value/No } \\
\text { value }\end{array}$ \\
\hline Direct work & $x$ & & $x$ \\
\hline Rework & & $x$ & No value \\
\hline Coordination & & $x$ & No value \\
\hline Decision wait & & $x$ & No value \\
\hline
\end{tabular}

The core of this research is the importance of being able to model activities related to flows, i.e., communication activities, inspections, waiting times for decisions and responses, among others, maintaining the concern in the transformation processes (see Table 1). VDT allows modeling the above, taking into account organizational aspects, such as the experience of people, skills, the level of hierarchy, obtaining as a result the cost, time and related parameters to quality.

\section{Research Methodology}

The research methodology consisted on the following stages:

-Stage 1: Exploring simulation tool, formalizing variables and developing tools to capture information.

-Stage 2: Gathering information for modeling projects.

-Stage 3: Creating and simulation of models.

-Stage 4: Models validation.

In the first stage we proceeded to explore the simulation tool to see its scope and functionality, through exploration cases, and to formalize VDT variables to be included in the study. Finally, mechanisms and instruments for collecting information on participating companies were developed. In the second stage, we proceeded to collect information from four construction projects of a traditional construction company (three projects were of remodeling and one was strictly traditional construction project) and the strategic process of a public construction concessions company. This was done through interviews, site visits, obtaining tender files with project information and surveys to rescue information related to input parameters of SimVision and flow processes. The third step was the creation of models and their respective simulation, to move to the fourth stage of models validation. In that stage, modeling results and actual projects performance were compared, making successive iterations to find the probabilities of VDT that best reflected the performance of projects organizations studied. The selection criterion was to choose the odds that managed a minor percentage to $5 \%$ difference between the real and modeling. Subsequently, companies were visited to carry out the approval of the results of the models using a structured interview with technical experts from each company, to rescue the standpoint of the organizations studied related to the results and obtain approval in the analyzed factors.

Results

\section{Data collection and probabilities calibration}

Table 2 summarizes the variables involved in the investigation. A model was constructed for each project. The validation of the models was comprised by two parts: first a quantitative manner, through the calibration of parameters, and secondly, qualitatively, using a structured interview that contained 14 aspects (see Table 5 in Appendix section) covered by the models, and that would be subject to assessment of the quality of predictions by the judgment of technical experts.

\begin{tabular}{|c|c|c|}
\hline VDT variable & Use in the model & Obtaining mode \\
\hline \multicolumn{3}{|l|}{ Cultural properties } \\
\hline $\begin{array}{l}\text { In form a tion } \\
\text { Exch a n g e } \\
\text { Probability }\end{array}$ & $\begin{array}{l}\text { Input - Dependent } \\
\text { variable }\end{array}$ & Calibration \\
\hline Noise Probability & $\begin{array}{l}\text { Input - Dependent } \\
\text { variable }\end{array}$ & Calibration \\
\hline $\begin{array}{l}\text { Functional Error } \\
\text { Probability }\end{array}$ & $\begin{array}{l}\text { Input - Dependent } \\
\text { variable }\end{array}$ & Calibration \\
\hline $\begin{array}{ll}\text { Project } & \text { Error } \\
\text { Probability } & \end{array}$ & $\begin{array}{l}\text { Input - Dependent } \\
\text { variable }\end{array}$ & Calibration \\
\hline Team Experience & $\begin{array}{l}\text { Input - Independent } \\
\text { variable }\end{array}$ & Survey and interview \\
\hline Formalization & $\begin{array}{l}\text { Input - Independent } \\
\text { variable }\end{array}$ & Survey and interview \\
\hline Centralization & $\begin{array}{l}\text { Input - Independent } \\
\text { variable }\end{array}$ & Survey and interview \\
\hline Matriz Strenght & $\begin{array}{l}\text { Input - Independent } \\
\text { variable }\end{array}$ & Survey and interview \\
\hline \multicolumn{3}{|l|}{ Related to activities } \\
\hline Rework links & $\begin{array}{l}\text { Input - Independent } \\
\text { variable }\end{array}$ & Survey \\
\hline Communication links & $\begin{array}{l}\text { Input - Independent } \\
\text { variable }\end{array}$ & Survey \\
\hline Durations & $\begin{array}{l}\text { Input - Independent } \\
\text { variable }\end{array}$ & Planning files \\
\hline Costs & $\begin{array}{l}\text { Input - Independent } \\
\text { variable }\end{array}$ & $\begin{array}{l}\text { budget and cost } \\
\text { control files }\end{array}$ \\
\hline \multicolumn{3}{|c|}{ Related to responsibles } \\
\hline Role of professionals & $\begin{array}{l}\text { Input - Independent } \\
\text { variable }\end{array}$ & Survey and interview \\
\hline $\begin{array}{l}\text { A p p I i c a t ion } \\
\text { Experience }\end{array}$ & $\begin{array}{l}\text { Input - Independent } \\
\text { variable }\end{array}$ & Survey and interview \\
\hline Responsabilities & $\begin{array}{l}\text { Input - Independent } \\
\text { variable }\end{array}$ & Planning files \\
\hline \multicolumn{3}{|l|}{ Related to outputs } \\
\hline Project schedule & $\begin{array}{l}\text { Output - Independent } \\
\text { variable }\end{array}$ & Final work trace files \\
\hline Project costs & $\begin{array}{l}\text { Output - Independent } \\
\text { variable }\end{array}$ & Final work trace files \\
\hline Project quality & $\begin{array}{l}\text { Output - Independent } \\
\text { variable }\end{array}$ & Final work trace files \\
\hline
\end{tabular}

Some reference input probabilities were obtained from a previous study of VDT (Ibrahim \& Nissen, 2004), which got a 0.7 for Information Exchange Probability, 0.2 for Noise and 0.05 
for Functional and Project Error Probabilities. The SimVision manuals also recommend some values for probabilities, based on the experience of its developers, however, to apply them in a different country (which has a particular context and projects), you need to look values that could be representative. In general, the calibration consisted in modelling projects with initial fixed amounts of work, with values of probabilities set in 0 , to then modifying them until the cost and Time of each model exceeded at most $5 \%$ the real project performance in each case.

For Company 1 , the probabilities of the model were calibrated based on historical information of the construction process, taking into account data from three previous projects. Probabilities calibrated for each case were obtained and turned out to be different when the time horizon of activities was different too. For this reason, two sets of probabilities were obtained (see Table 3), one for project activities with a shorter time horizon (days or weeks) and one for more extensive activities (months). However, both results are not so different from the benchmarks of literature: the probabilities of Information Exchange and Noise are kept. In the short term, Functional and Project Error Probabilities differ by one percentage point above benchmark, and in the long-term, Probabilities differ by two percentage points lower.

For Company 2, the probabilities were calibrated for each project to obtain a result separately. Then to get a set of probabilities that was representative of the Company, they were averaged and each model was tested to see how they worked and if predictions within the range set would be obtained. In addition, a third process of calibration was performed. It was more refined than the simple average and consisted in averaging the probabilities of three models to try to predict the results of the fourth. In this calibration process was discovered that the project that had different nature had higher levels of Functional and Project Error probabilities, in the order of 0.18 , rather closer to 0.2 proposed as a starting point in the manual of SimVision (ePM LLC, 2005). Taking this into consideration, the final result is pretty close to the ones obtained in literature: Functional and Project Error Probabilities vary by three percentage points over the benchmark. These results when compared with literature parameters are positive, since they are pretty close.

$\begin{aligned} & \text { Table 3. Probabilities calibration results by company. Source: Own realization, } \\
& 2014 .\end{aligned}$
\begin{tabular}{lccc} 
VDT calibrated probability & \multicolumn{2}{c}{ Company 1} & \multirow{2}{*}{ Company 2} \\
\cline { 2 - 3 } & Short term & Long term & \\
\hline $\begin{array}{l}\text { Information Exchange } \\
\text { Probability }\end{array}$ & 0,700 & 0,700 & 0,733 \\
\hline Noise Probability & 0,200 & 0,200 & 0,300 \\
\hline Functional Error Probability & 0,060 & 0,030 & 0,080 \\
\hline Project Error Probability & 0,060 & 0,030 & 0,080 \\
\hline
\end{tabular}

The results of the calibration are shown in Table 3. This results were subject to approval by each company's technical experts, through structured interviews in order to assess the quality of predictions. The answers are based on how well the models predict the actual results of the projects (seeing the differences obtained between modeled and real performance), and under the judgment of each professional in relation to the prediction of each model makes sense to the observed in field in each project.
Figure 1. Percentages obtained in each category for the 14 principles evaluated in the structured interview. Source: Own realization, 2014.

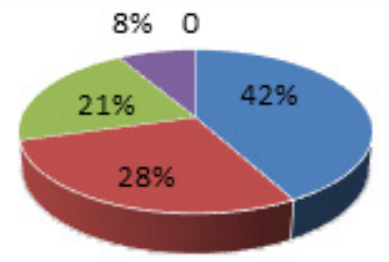

- Very Good

- Good

- Regular

- Deficient

- Very Deficient

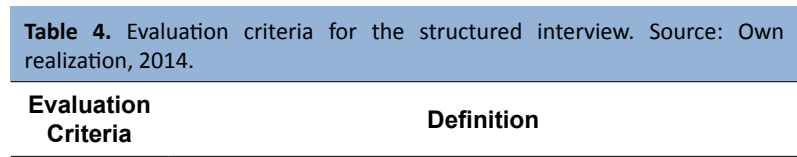

$\mathrm{N} / \mathrm{A}$ (Not Marked when the queried feature has no connection with Applicable) the investigation or study it was not possible.

\begin{tabular}{|c|c|}
\hline $\begin{array}{c}\text { Very } \\
\text { Deficient }\end{array}$ & $\begin{array}{l}\text { Marked when the prediction of the model is totally } \\
\text { different from the reality. In quantitative terms, where } \\
\text { prediction is far more than } 30 \% \text { of actual results. In } \\
\text { terms of graphic parameters, when the prediction is } 3 \\
\text { categories above or below the real result (usually there } \\
\text { are } 4 \text { categories, green level - optimum, level yellow - } \\
\text { normal, orange level - warning, red level - dangerous). }\end{array}$ \\
\hline Poor & $\begin{array}{l}\text { Marked when the model prediction is considerably } \\
\text { different from reality. Quantitatively, between } 15 \% \text { and } \\
30 \% \text { of difference with real results. In terms of graphic } \\
\text { parameters, when the prediction is } 2 \text { categories above } \\
\text { or below the real result. }\end{array}$ \\
\hline Regular & $\begin{array}{l}\text { Marked when the model prediction is not as close to } \\
\text { reality, but not so far. Quantitatively, when it is between } 5 \\
\text { and } 15 \% \text { of reality. In terms of graphic parameters, when } \\
\text { the prediction is } 1 \text { category in comparison to the actual } \\
\text { result. }\end{array}$ \\
\hline Good & $\begin{array}{l}\text { Marked when the prediction model is closer to reality, but } \\
\text { not as accurate. In quantitative terms, when it is between } \\
3 \text { to } 5 \% \text { of reality. In terms of graphic parameters, when } \\
\text { the prediction is in the same category as compared to } \\
\text { the actual outcome, but closer to the lower or higher } \\
\text { category than the real result. }\end{array}$ \\
\hline Very Good & $\begin{array}{l}\text { Marked when the prediction model is very close to reality. } \\
\text { In quantitative terms, when it is } 3 \% \text { or less of reality. In } \\
\text { terms of graphic parameters, when the prediction is in } \\
\text { the same category as compared with real performance } \\
\text { and very close to the actual result. }\end{array}$ \\
\hline
\end{tabular}

In the Table 4 the evaluation criteria of the structured interview is presented. The results of the interviews (see Table 5 in Appendix) grouped responses on seven projects (three of Firm 1 and four of Firm 2), with a total of 95 predictions (three were removed, since they fall under "Not Applicable" category). Of these, the mode category corresponded to "Very Good" with a 42.11\% (see Figure 1). The following was the "Good" category, with $28.42 \%$ of all predictions. That is, the $70.53 \%$ of the cells obtained a positive rating, which means that nearly $71 \%$ of the aspects were within $5 \%$ difference between real performance and models results. It is also important to note that the response "Regular" obtained a $21.05 \%$, being the third most mentioned category and achieving an aggregate percentage (sum of the other two categories) of $91.58 \%$, indicating that about $92 \%$ of predictions were in regular limits at least. Furthermore, generally aspects that scored category "Regular" tended to be those most difficult to measure and substantiate in practice, such as Product Quality and Process. This tended to encourage experts to respond "Regular" in those predictions, but they had the feeling that quality was achieved through their projects and generally is good. Finally, note that in the case of Firm 1 survey was answered by the Project Manager 
and in Firm 2 was answered by four professionals (Administration and Finance Manager, Technical Manager, Head of Quality Management, Head of Planning).

\section{Results Analysis}

In terms of modeling, it is possible to mention that models represent reality within appropriate margins given the variable nature of the problem studied, which is supported by obtaining parameters quite close to those found in the literature (Ibrahim $\&$ Nissen, 2004). Among the difficulties of the process, it is possible to mention that the Functional and Project Error Probabilities are a little low compared to that observed in the experience of the VDT's expert modelers. This could be because the performance workers rates that are handled in planning departments already include some coordination work, so in the initial models net direct labor is increased, causing lower rework probabilities. This issue was mitigated by adjusting the yields according to specialist journals, as ONDAC, but anyway here they have some coordination work included.

The satisfaction survey showed the category "Very Good" in 47 responses as the mode, followed by the "Good" category with 31 responses, realizing that generally practitioners approved the results obtained by the models. The best aspects achieved and evaluated are the capture of activities that most coordination and rework generated, followed by the cost and time, which generally had positive rating, agreeing with the good results achieved in models relating to these topics. The worst aspects achieved by the models correspond to the timing of activities occurrence and the timing of workers backlogs occurrence, because models failed in predict them. However, they were not likely to achieve this, because project managers from the projects studied did not follow the Gantt chart in a strict order, but carried out the activities to the extent that it was possible to do so without releasing restrictions to further planning. For this reason, it doesn't matter so much that qualification assigned had gone wrong because it was expected that this could not be predicted. The same applies to the issues of process quality and product, where it is qualitative information, that can be obtained based more on perceptions, so it is not critical obtain consistent qualitative results in their predictions.

\section{Discussion}

This research aimed to obtaining VDT probabilities inputs to serve as a future reference to similar projects in construction companies to help them design construction projects, incorporating organizational elements and a production theory of transformation, flow and value. The calibrated models results obtained represent reality within appropriate margins given the variable nature of the problem, being able to predict the performance of projects with results generally less than $5 \%$ difference between the real performance and modeling results, and well received by companies in the structured interview, with over $70 \%$ approval in the predicted factors covered. It is noteworthy that beyond the accuracy of the results, the key is the anticipation of potential future events and circumstances, an useful functionality of organization modeling. Possible future work could focus on achieving obtaining input parameters of the models that are transverse to the construction sector, by size / type of company, having filters according to category, terms and conditions. Another possible focus of study is the evaluation of the implementation of Lean Management methodology in organizational settings, and their subsequent comparison with model predictions.

\section{References}

Carroll, T.N., Gormley, T.J., Bilardo, V.J., Burton, R.M. Y Woodman, K.L. (2006). Designing a New Organization at NASA: An Organization Design Process Using Simulation. Organization Science, 17(2), 202-214

ePM, LLC (2002). CASOS 2002 - VDT Case Study: Design-Build Biotech Plant Case.

ePM, LLC (2005). SimVision Tutorial: UserGuide.

Galbraith, J. (1974). Organization design: An information processing view. Interfaces. 4 (1974), 28-36.

Ghio, V.A. \& Bascuñán, R. (1995). Innovación Tecnológica en la Construcción Ahora es Cuando. Revista Ingeniería de Construcción, 14.

González, V. \& Alarcón, L.F. (2003). Buffers de Programación: una estrategia complementaria para reducir la variabilidad en los procesos de construcción. Revista Ingeniería de Construcción, 18 (2), 109-119.

Ibrahim, R. \& Nissen, M. (2004). Simulating environmental contingencies using SimVision ${ }^{\circledast}$, Proceedings of the NAACSOS Conference 2004 in Pittsburgh, Pensylvannia, June 27-29 by the North American Association for Computational Social and Organization Science.

Khosraviani, B. \& Levitt, R.E. (2005). An Evolutionary Approach for Project Organization Design: Producing Human-Competitive Results Using Genetic Programming (PhD thesis). Stanford University, Stanford, California.

Koskela, L. (2000). An exploration towards a production theory and its application to construction (PhD thesis). Helsink University of Technology, Espoo, Finland.
Kunz, J.C., Levitt, R.E. \& Thomsen, J. (1997). Intervention studies Using the Virtual Design Team, Center for Integrated Facility Engineering. California: Universidad de Stanford.

Magendzo, I. \& Villena, M. (2012). Evolución de la Productividad Total de Factores en Chile. Informe Técnico, Universidad Adolfo lbáñez.

Levitt, R. \& Kunz, J. (2002). Design your Project Organization as Engineers Design Bridges, CIFE Working Paper \#73, Center for Integrated Facility Engineering, Universidad de Stanford.

Levitt, R. (2009). Overview of The Virtual Design Team (VDT) Research Program: 1988-2010, CIFE Working Paper \#52, Center for Integrated Facility Engineering, Universidad de Stanford.

Louie, M.A. (2002). A docking Study of SimVision and ORGAHEAD DRAFT, Department of Engineering and Public Policy, Carnegie Mellon University, Pittsburgh, PA 15213.

Nissen, M.E. \& Buettner, R.R. (2004). Computational Experimentation with the Virtual Design Team: Bridging the Chasm between Laboratory and Field Research in C2, en Proceedings Command \& Control Research \& Technology Symposium, San Diego, CA, June.

Orozco, F., Serpell, A. \& Molenaar, K. (2011). Competitiveness factors and indexes for construction companies: findings of Chile. Revista de la Construcción, 10 (1), 91-107.

Serpell, A. \& Alarcón, L.F. (2007), Planificación y control de proyectos, Segunda edición, Santiago: Ediciones Universidad Católica. 
Structured Interview to Validate Virtual Models

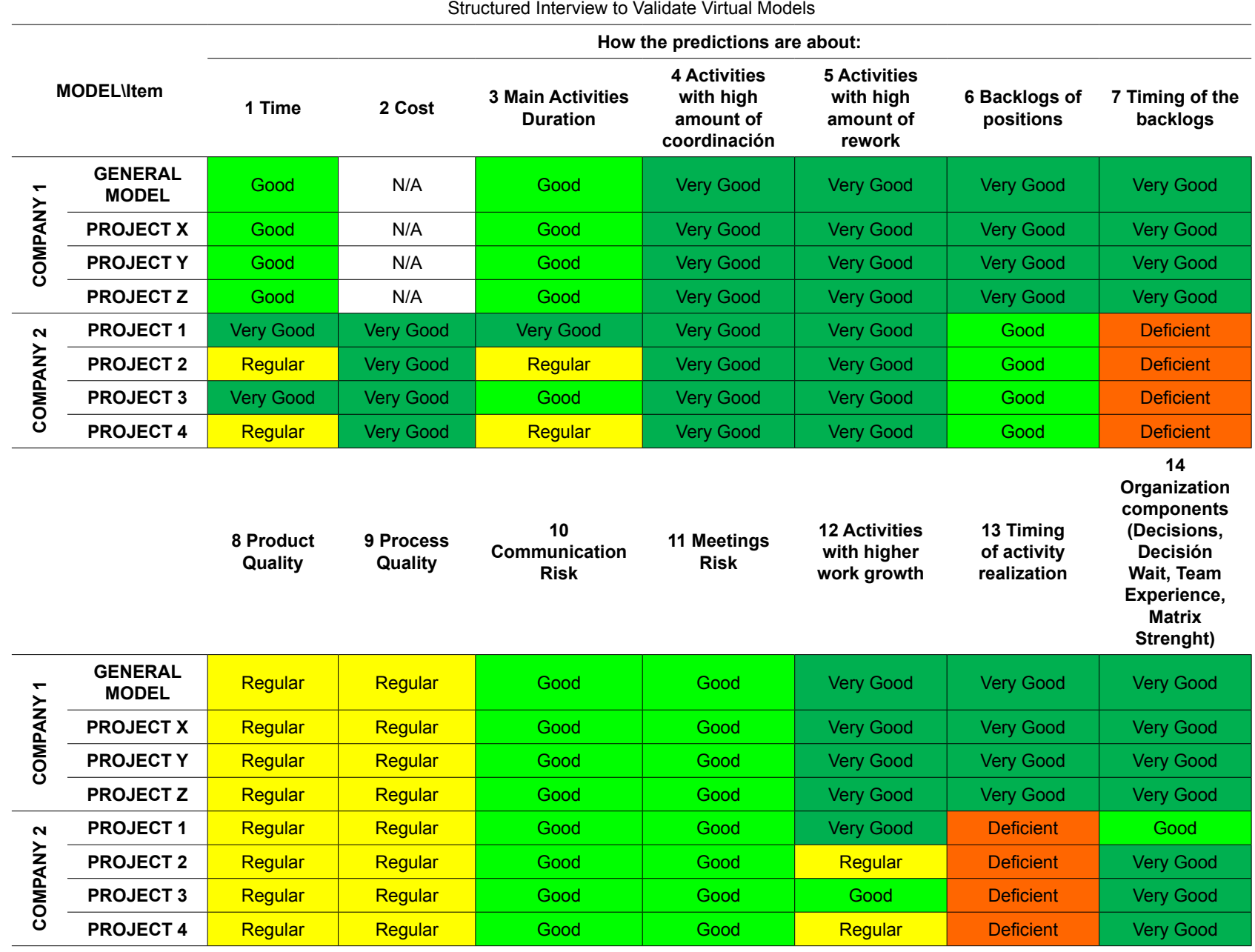

